\section{SOBRE EL PERU Y SOBRE EL DR. DE LA PUENTE CANDAMO} (Homenaje por sus cincuenta años en la docencia universitaria)

Nacido el 22 de mayo de 1922 en la hacienda Orbea, ubicada en la Magdalena Vieja, José Agustín de la Puente Candamo inició sus estudios primarios con instructores privados, para luego realizar su formación secundaria en el colegia de Ia Recoleta, finalizándolos en el año de 1938.

$\mathrm{Al}$ año siguiente, y contando con diecinueve años de edad, ingresaba a la Universidad Católica del Perú en donde siguió estudios en las facultades de Letras y Derecho; ostentando el grado de Bachiller en Humanidades en 1941 con la tesis Planes Monárguicos de San Martín y, en 1946, en Derecho con la tesis Problema juridico de la conquista de América.
Contando con veinticinco años de edad, en el año de 1947, no solamente obtuvo el título de abogado, sino que se graduaba como doctor en Historia sustentando la tesis San Martin y el Peni. Planteamiento doctrinario, por el cual fue galardonado con el premio nacional de Historia "Inca Garcilazo de la Vega", obra que fue editada posteriormente como libro al año siguiente.

Para el mismo año comenzaba su labor como docente en la Universidad Católica, labor que ejerce hasta nuestros días en la condición de catedrático titular de Historia del Perú en lo referente a la etapa emancipadora, $y$ lo cual ha sido la razón del homenaje póstumo a su persona.

El doctor De la Puente Candamo ha sido también honrado con la administración de varias instituciones relacionadas al quehacer intelectual, así, por ejemplo, el decanato de la Facultad de Letras (1957-1963) y la jefatura del Departamento de Humanidades (1992. 1996) de la Universidad Católica; Director del Instituto Peruano de 
Cultura Hispánica (1962-1964); Subdirector(1964-1967), director (1967-1981) y director emérito (1998) del Instituto Riva-Agüero; Presidente de la Academia Nacional de Historia (1995-2000), y autor de importantes investigaciones.

Es por eso que el año pasado (2002), la Facultad de Letras y Ciencias Humanas, en la persona de la Dra. Liliana Regalado Hurtado, ha visto bien en rendir un homenaje al doctor De la Puente Candamo, por motivo de haber cumplido cincuenta años al servicio de la docencia de la Pontificia Universidad Carólica del Perú. $Y$ no hubo mejor manera, que hacerlo mediante un klibro-homenaje» denominado Sobre el Perú (2 vols., 1375 pp.) en donde discípulos, amigos y colegas del doctor De la Puente presentan una variedad de investigaciones en donde se puede ver la intervención de las enseñanzas del ilustre intelectual.

En el primer volumen de la obra encontramos seis discursos de agradecimiento a la persona del doctor De la Puente Candamo, discursos realizados por sus amigos y colegas de la PUCP. Seguidamente se presentan dos testimonios y una biografia, para luego pasar a los treinta y tres primeros artículos de la obra. En el segundo volumen encontramos las investigaciones restantes.

Los attículos nos llevan a internarnos en los tres momentos de nuestra historia (Autóctona, Colonia y República), así tenemos, por ejemplo, sobre el período autóctono: "Vicús: revisión e inferencias icnográficas", de Federico Kauffmann Doig; "LLos infinitos tesotos del antiguo Perúu por María Rostwotowski; «La Formación del estado en la civilización andinas por Fernando Silva-Santisteban. En lo referente a la Colonia tenemos trabajos como: "Toribio Alfonso Mogrovejo», «santo forjador del Perús por nuestro colega el Dr. José Antonio Benito Rodriguez; "Españoles en la Villa de Cajamarca a mediados del siglo XVIL por Waldemar Espinoza Soriano y, en lo concerniente a nuestra historia republicana, también tenemos, entre otros: «Ideologías del Perú republicano del siglo XIXy de Rafael SánchezConcha Barrios y «obre un supuesto "cuadrillazo" para atacar Chile en 1892》, de Luis Santiago Sanz.

Obra que creemos bien merecida para el doctor De la Puente Candamo, y que no debetia faltar en ninguna biblioteca seria de nuestro pais 
especialmente por los grandes y novedosos aportes para la comprensión de nuestra historia.

Pedro P. Soto Canales

Profesor de Historia

Universidad Católica Sedes Sapientiae 